STRUCTURAL BIOLOGY COMMUNICATIONS

ISSN 2053-230X

Received 20 February 2018

Accepted 16 April 2018

Edited by S. Sheriff, Bristol-Myers Squibb, USA

Keywords: PX domain; PH domain; phox; pleckstrin homology; phosphatidylinositol phosphates; PIP; Saccharomyces cerevisiae; Bem3.

PDB reference: tandem PX-PH domains of Bem3 from S. cerevisiae, $6 \mathrm{fsf}$

Supporting information: this article has supporting information at journals.iucr.org/f

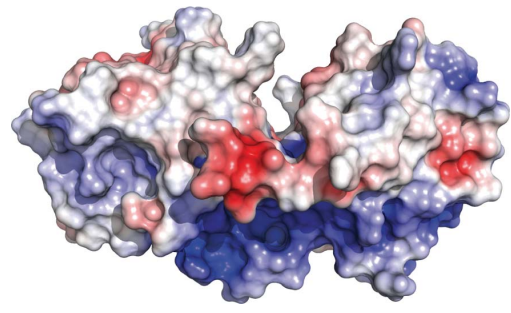

OPEN $\odot$ ACCESS

\section{Structure of the tandem PX-PH domains of Bem3 from Saccharomyces cerevisiae}

\author{
Imtiaz Ali, ${ }^{a}$ Sungmin Eu, ${ }^{\mathrm{a}}$ Daniel Koch, ${ }^{\mathrm{a}}$ Nathalie Bleimling, ${ }^{\mathrm{a}}$ Roger S. Goody ${ }^{\mathrm{a} *}$ and \\ Matthias P. Müller ${ }^{\mathrm{a}, \mathrm{b}}$ * \\ ${ }^{a}$ Department of Structural Biochemistry, Max Planck Institute of Molecular Physiology, Otto-Hahn-Strasse 11, \\ 44227 Dortmund, Germany, and ${ }^{\mathbf{b}}$ Faculty of Chemistry and Chemical Biology, TU Dortmund University, \\ Otto-Hahn-Strasse 4a, 44227 Dortmund, Germany. *Correspondence e-mail: roger.goody@mpi-dortmund.mpg.de, \\ matthias3.mueller@tu-dortmund.de
}

The structure of the tandem lipid-binding PX and pleckstrin-homology (PH) domains of the Cdc42 GTPase-activating protein Bem3 from Saccharomyces cerevisiae (strain S288c) has been determined to a resolution of $2.2 \AA\left(R_{\text {work }}=\right.$ $21.1 \%, R_{\text {free }}=23.4 \%$ ). It shows that the domains adopt a relative orientation that enables them to simultaneously bind to a membrane and suggests possible cooperativity in membrane binding.

\section{Introduction}

The Bem3 protein from Saccharomyces cerevisiae (UniProt ID P32873) is a large multi-domain protein consisting of 1128 amino acids (Zheng et al., 1994). Three domains within the protein can be deduced from the amino-acid sequence: a PX domain (amino acids 504-630), a PH domain (amino acids 630-741) and a RhoGAP domain at the C-terminus of Bem3 (amino acids 913-1128) (Fig. 1). It has also been suggested that the N-terminal part of the protein (amino acids 1-114) is an auto-inhibitory module which results in a constitutively active variant of Bem3 upon deletion (Fig. 1; Kadota et al., 2004; Mukherjee et al., 2013).

The PX domain, which was discovered as a conserved sequence of 100-140 amino acids (Ponting, 1996), has been identified in more than 100 yeast and mammalian proteins belonging to diverse families (Ellson et al., 2002; Sato et al., 2001; Seet \& Hong, 2006; Xu et al., 2001). The conserved three-dimensional structure contains an $\mathrm{N}$-terminal $\beta$-sheet followed by a helical subdomain with three $\alpha$-helices ( $\mathrm{Lu}$ et al., 2002). Conserved basic residues present in the $\beta 3-\alpha 1$ region of the PX domain are believed to mediate interaction with the phosphate groups of phosphatidylinositol phosphates (PIPs) within membranes (Cheever et al., 2001; Ellson et al., 2001; Song et al., 2001; Xu et al., 2001). These PIPs are phosphorylated derivatives of phosphatidylinositol that constitute a small fraction of the total cellular lipids but are important components of cellular organization (Lenoir \& Overduin, 2013). Phosphorylation at the $3^{\prime}-, 4^{\prime}-$ and $5^{\prime}$ hydroxyl groups of the inositol ring leads to seven different phosphatidylinositol phosphates. Each of these singly, doubly or triply phosphorylated PIPs displays a distinct localization in cellular organelles, where they recruit specific PIP-binding effectors to exert their regulatory functions, such as lipid signalling, vesicle transport and cell growth (Lenoir \& Overduin, 2013; Mayinger, 2012). The specificity and affinity towards certain PIPs can vary between different PX domains 
(Song et al., 2001). Whereas many PX domains exhibit a common preference for PI3P as the primary binding partner on membranes, others bind less specifically and recognize different PIPs (Mayinger, 2012). The low binding affinity for PI3P observed in some PX-domain-containing proteins is associated with the presence of a secondary lipid-binding site within this domain which specifically binds to phosphatidic acids (PAs) or phosphatidylserine (PS), as well as other PIPs, and can synergistically cooperate with the primary PI3P binding of the PX domain (Karathanassis et al., 2002; Stahelin et al., 2004). Apart from the secondary lipid-binding site, the possible oligomerization of some proteins owing to the PX domain can further enhance the interaction between these proteins and membranes (Xing et al., 2004).

The second important PIP-binding domain found in Bem3 is the pleckstrin-homology $(\mathrm{PH})$ domain, which directly follows the PX domain within the primary sequence of Bem3 and consists of approximately 100 amino acids (Haslam et al., 1993). The structure of PH domains consists of seven strongly bent antiparallel $\beta$-strands, which are terminated by a C-terminal $\alpha$-helix (Blomberg et al., 1999; Macias et al., 1994; Saraste \& Hyvönen, 1995; Yoon et al., 1994). Sequencesimilarity searches in the human protein database led to the identification of this domain in more than 250 proteins,
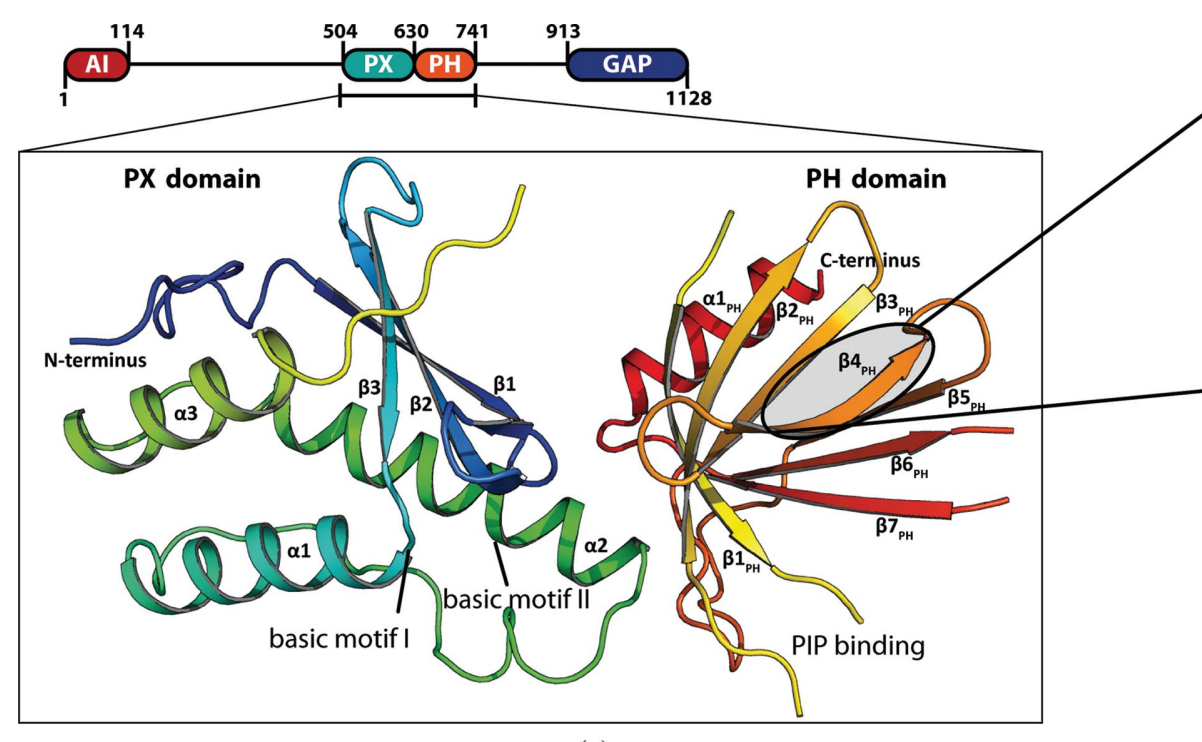

(a)
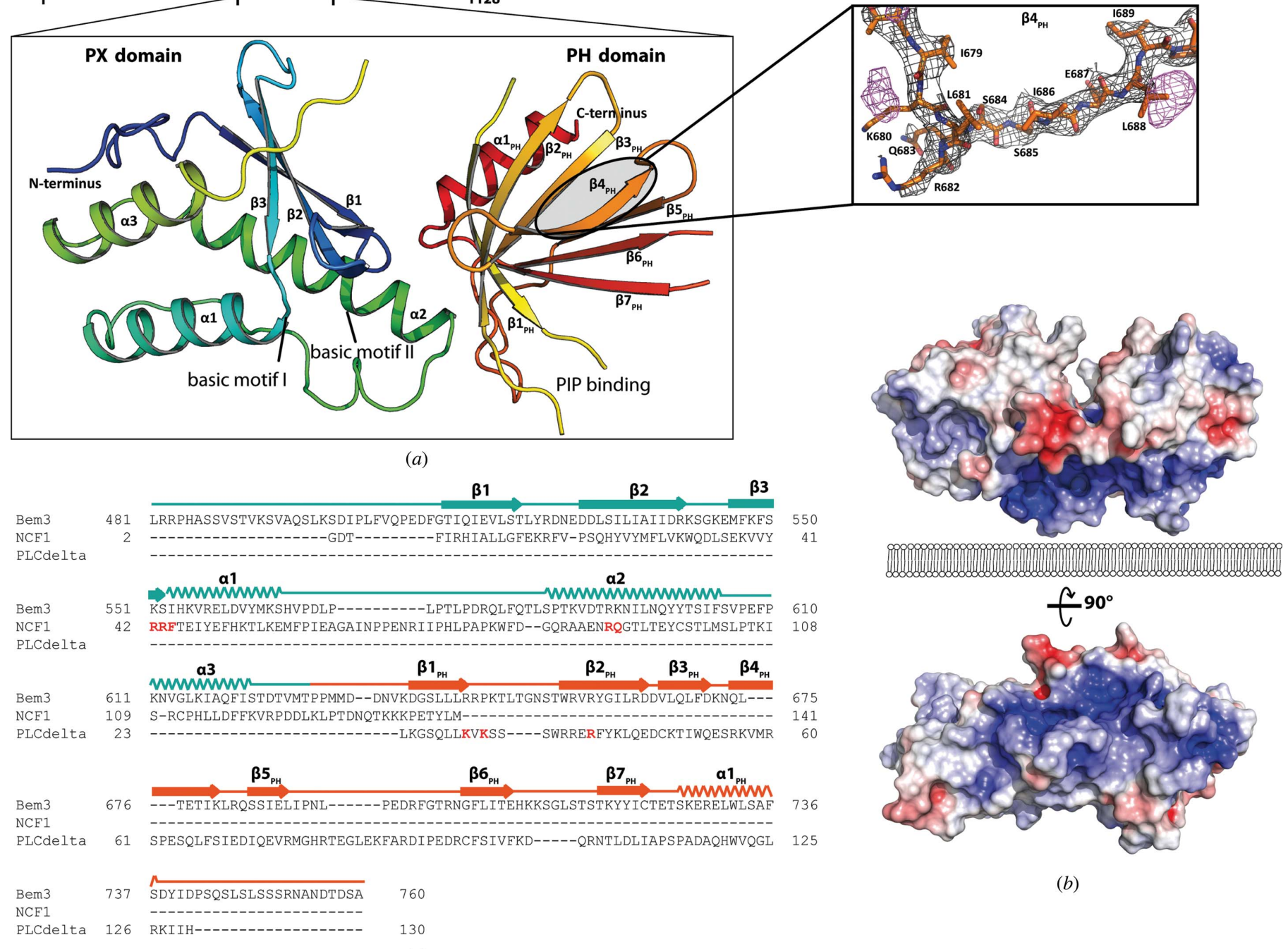

(b)

Figure 1

(c)

(a) Domain architecture of Bem3 and cartoon representation of the PX and PH domains of Bem3 and their relative positions within the full-length protein. Important regions that are putatively involved in membrane binding are indicated for both domains. The inset additionally shows a magnified view of $\beta 4_{\mathrm{PH}}$ where the electron density did not allow unambiguous assignment of the amino-acid side chains $\left(2 m F_{\mathrm{o}}-D F_{\mathrm{c}}\right.$ electron density shown in black at an r.m.s.d. of 1). Therefore, the anomalous signal from the SeMet-derivative crystals was used to correctly assign the position of amino acids (anomalous map in magenta depicted at an r.m.s.d. of 4). (b) Electrostatic potential of Bem3 contoured at $\pm 5 k T \mathrm{e}^{-1}$ calculated with $A P B S$ (Baker $e t$ al., 2001) shown in two orientations including the highly basic putative membrane-binding site [the upper figure is shown in the same orientation as in (a), the membrane is indicated below the structure]. All structural representations were prepared with PyMOL (DeLano \& Lam, 2005). (c) Sequence alignment produced with PROMALS3D (Pei et al., 2008) of Bem3 with the PX domain of Ncf1 (UniProt ID P14598) and the PH domain of PLC $\delta$ (UniProt ID P10688). Important residues that belong to the basic motifs I and II (PX domain; Sato et al., 2001) and the PIP-binding region within the PH domain (Lemmon, 2007) are highlighted in red. 
Table 1

Macromolecule-production information.

Recognition sequences are underlined in the primer sequences.

\begin{tabular}{|c|c|c|}
\hline & Bem $3_{500-765}$ & Bem $3_{500-750}$ \\
\hline DNA source & Genomic DNA (strain S288c) & Genomic DNA (strain S288c) \\
\hline Forward primer & AAAAAACATATGAAGTCGGATATTCCATTATTCGTTCAACCGG & AAAAAACATATGAAGTCGGATATTCCATTATTCGTTCAACCGG \\
\hline Reverse primer & $\begin{array}{l}\text { AAAAAA } \overline{\text { GGATCCTCATGCGCTCAAGTGAGATGCAGAATCAGTA }} \\
\text { TCG }\end{array}$ & $\begin{array}{l}\text { AAAAAA } \overline{C T C G A G T C A G C T A G A T A A C G A T A A A C T T T G T G A A G G A ~} \\
\text { TCAATG }\end{array}$ \\
\hline Expression vector & pET-19mod & pET-19mod \\
\hline Expression host & E. coli $\mathrm{BL} 21-\mathrm{CodonPlus}$ (DE3)-RIL & E. coli BL21-CodonPlus (DE3)-RIL \\
\hline \multirow{7}{*}{$\begin{array}{l}\text { Complete amino-acid sequence } \\
\text { of the construct produced }\end{array}$} & GHMKSDIPLFVQPEDFGTIQIEVLSTLYRDNEDDLSILIAIID & GHMKSDIPLFVQPEDFGTIQIEVLSTLYRDNEDDLSILIAIID \\
\hline & RKSGKEMFKESKS I HKVRELDVYMKSHVPDLPLPTLPDRQL & RKSGKEMFKFSKS I HKVRELDVYMKS HVPDLPLPTLPDRQL \\
\hline & FQTLSPTKVDTRKNILNQYYTSIFSVPEFPKNVGLKIAQFI & FQTLSPTKVDTRKNILNQYYTS IFSVPEFPKNVGLKIAQFI \\
\hline & STDTVMTPPMMDDNVKDGSLLLRRPKTLTGNSTWRVRYGIL & STDTVMTPPMMDDNVKDGSLLLRRPKTLTGNSTWRVRYGIL \\
\hline & RDDVLQLFDKNQLTETIKLRQSS IELIPNLPEDRFGTRNGF & RDDVLQLFDKNQLTETIKLRQSS IELIPNLPEDRFGTRNGF \\
\hline & LITEHKKSGLSTSTKYYICTETSKERELWLSAFSDYIDPSQ & LITEHKKSGLSTSTKYYICTETSKERELWLSAFSDYIDPSQ \\
\hline & SLSLSSSRNANDTDSASHLSA & SLSLSS \\
\hline
\end{tabular}

making it the 11th most abundant domain in the human proteome (Letunic et al., 2006). PH domains preferably bind to PIPs that have adjacent phosphates, such as $\mathrm{PI}(4,5) \mathrm{P}_{2}$, $\mathrm{PI}(3,4) \mathrm{P}_{2}$ and $\mathrm{PI}(3,4,5) \mathrm{P}_{3}$. However, only a minor fraction of these domains show high affinity and specificity for one PIP, whereas other $\mathrm{PH}$ domains either do not recognize PIPs or interact very weakly and the functional significance of their interactions is not clear (Isakoff et al., 1998; Kavran et al., 1998; Lemmon \& Ferguson, 2000; Takeuchi et al., 1997; Yu et al., 2004). In addition to PIP binding, the $\beta$-sandwich structure of $\mathrm{PH}$ domains is involved in various other functions, including protein-protein interactions as well as oligomerization (Baumeister et al., 2003; Klein et al., 1998; Worthylake et al., 2004, Lemmon, 2007).

In this study, we have determined the X-ray crystallographic structure of the interesting tandem PX-PH domain module of Bem 3 to a resolution of $2.2 \AA$, showing that the putative membrane-binding regions of both domains are oriented in the same direction and thus might act synergistically in membrane recognition and binding.

\section{Experimental procedures}

\subsection{Plasmid construction}

Bem3 constructs encompassing the regions containing amino acids 500-765 or 500-750 (comprising the PX and PH domains of Bem3) were amplified from yeast genomic DNA (strain S288c) using Pfu polymerase (NEB, England) and the primers listed in Table 1 . The amplicons were digested with the respective restriction enzymes (NdeI, BamHI and XhoI; the recognition sequences are underlined in the primer sequences) and incorporated into a modified bacterial expression plasmid (pET-19mod). The resulting constructs were used for the expression of Bem 3 including an N-terminal hexahistidine tag followed by a Tobacco etch virus (TEV) protease cleavage site. For phasing and unambiguous assignment of the amino-acid sequence in the structure, point mutations were introduced by site-directed mutagenesis at positions $680(\mathrm{~K} 680 \mathrm{M})$ and $688(\mathrm{~L} 688 \mathrm{M})$ to incorporate L-selenomethionine (SeMet).

\subsection{Protein purification}

To express the recombinant proteins, Escherichia coli BL21-CodonPlus (DE3)-RIL cells were transformed with the corresponding plasmid and allowed to grow at $37^{\circ} \mathrm{C}$ until the $\mathrm{OD}_{600}$ reached approximately $0.60-0.65$. Expression was induced by adding isopropyl $\beta$-D-1-thiogalactopyranoside (IPTG) to a final concentration of $0.2 \mathrm{mM}$ and growth was continued overnight at $20^{\circ} \mathrm{C}$. The SeMet-labelled mutants were expressed using conditions described elsewhere (Van Duyne et al., 1993).

The cells were harvested by centrifugation, resuspended in cell-lysis buffer [50 $\mathrm{m} M$ HEPES pH 8, $500 \mathrm{~m} M \mathrm{LiCl}, 5 \%(v / v)$ glycerol, $2 \mathrm{~m} M \beta$-mercaptoethanol ( $\beta$-ME), $1 \mathrm{~m} M$ PMSF and a protease-inhibitor cocktail including $50 \mu \mathrm{g} \mathrm{ml}^{-1}$ chymostatin, leupeptin, antipain and pepstatin (Sigma)] and disrupted in a fluidizer (Microfluidics). The lysate was incubated with $1 \%$ CHAPS for $30 \mathrm{~min}$. Insoluble material was removed by centrifugation at $50000 \mathrm{~g}$ for $50 \mathrm{~min}$ at $10^{\circ} \mathrm{C}$ and the supernatant was applied onto an $\mathrm{Ni}^{2+}-\mathrm{NTA}$ HisTrap column pre-equilibrated with buffer $A$ [50 $\mathrm{m} M$ HEPES pH 8, $500 \mathrm{~m} M \mathrm{LiCl}, 5 \%(v / v)$ glycerol, $2 \mathrm{~m} M \beta$-ME]. After extensive washing of the column, His-tagged proteins were eluted with a linear gradient of buffer $B$ (buffer $A$ supplemented with $500 \mathrm{~m} M$ imidazole). The polyhistidine tag was cleaved overnight at $4^{\circ} \mathrm{C}$ using $0.06 \mathrm{mg} \mathrm{TEV}$ protease per milligram of recombinant protein during dialysis [the dialysis buffer consisted of $50 \mathrm{~m} M$ HEPES pH $8,100 \mathrm{~m} M \mathrm{NaCl}, 5 \%(v / v)$ glycerol, $2 \mathrm{~m} M \beta$-ME]. After a second $\mathrm{Ni}^{2+}-\mathrm{NTA}$ affinity purification to remove uncleaved protein and TEV protease, final purification was achieved by size-exclusion chromatography (Superdex 200 16/60, GE Healthcare) in the final storage buffer [20 $\mathrm{m} M$ HEPES pH 8, $100 \mathrm{~m} M \mathrm{NaCl}, 5 \%(v / v)$ glycerol, $2 \mathrm{~m} M$ dithioerythritol].

\subsection{Crystallization}

To determine the initial crystallization conditions, Bem3 was subjected to crystallization trials at $293 \mathrm{~K}$ by the sittingdrop vapour-diffusion method using the following commercially available protein crystallization screens: The PACT Suite, The PEGs Suite and The JCSG Core I-IV Suites 
Table 2

Crystallization conditions.

\begin{tabular}{|c|c|}
\hline Protein & $\begin{array}{l}\text { Bem3 }_{500-765} \text {, SeMet K680M Bem3 } \\
\text { SeMet } 6688 \mathrm{M} \text { Bem3 } \\
\text { Se0-750 }\end{array}$ \\
\hline Protein concentration $\left(\mathrm{mg} \mathrm{ml}^{-1}\right)$ & $33-48$ \\
\hline Temperature (K) & 293 \\
\hline Method & Hanging-drop vapour diffusion \\
\hline Drop ratio & $1 \mu \mathrm{l}+1 \mu \mathrm{l}$ \\
\hline $\begin{array}{l}\text { Buffer composition of protein } \\
\text { solution }\end{array}$ & $\begin{array}{l}20 \mathrm{~m} M \text { HEPES pH } 8.0,100 \mathrm{~m} M \mathrm{NaCl}, \\
2 \mathrm{~m} M \text { dithioerythritol, } 5 \% \text { glycerol }\end{array}$ \\
\hline Reservoir solution & $\begin{array}{l}500 \mu \mathrm{l} 0.1 M \text { PCB pH } 7.5-7.7,17-19 \% \\
\text { PEG } 1500\end{array}$ \\
\hline
\end{tabular}

Table 3

Data-collection and processing statistics.

Values in parentheses are for the outer shell.

\begin{tabular}{|c|c|c|c|}
\hline & $\mathrm{Bem}_{500-765}$ & $\begin{array}{l}\text { SeMet K680M } \\
\text { Bem } 3500-750^{\dagger}\end{array}$ & $\begin{array}{l}\text { SeMet L688M } \\
\text { Bem3 }_{500-750}{ }^{\dagger}\end{array}$ \\
\hline Diffraction source & X10SA, SLS & X10SA, SLS & X10SA, SLS \\
\hline Wavelength $(\AA)$ & 0.98013 & 0.97794 & 0.97793 \\
\hline Temperature (K) & 100 & 100 & 100 \\
\hline Detector & PILATUS $6 \mathrm{M}$ & PILATUS $6 \mathrm{M}$ & PILATUS $6 \mathrm{M}$ \\
\hline $\begin{array}{l}\text { Crystal-to-detector distance } \\
\quad(\mathrm{mm})\end{array}$ & 400.0 & 400.0 & 450.0 \\
\hline Rotation range per image $\left({ }^{\circ}\right)$ & 0.25 & 0.25 & 0.25 \\
\hline Total rotation range $\left({ }^{\circ}\right)$ & 180 & 720 & 720 \\
\hline ime per image (s) & 0.1 & 0.1 & 0.1 \\
\hline Space group & $P 6_{2}$ & $P 6_{2}$ & $P 6_{2}$ \\
\hline$a, b, c(\AA)$ & $\begin{array}{l}85.37,85.37 \\
\quad 63.97\end{array}$ & $\begin{array}{l}85.80,85.80 \\
\quad 65.01\end{array}$ & $\begin{array}{l}85.57,85.57 \\
\quad 64.02\end{array}$ \\
\hline$\chi, \beta, \gamma\left({ }^{\circ}\right)$ & $90,90,120$ & $90,90,120$ & $90,90,120$ \\
\hline Resolution range $(\AA)$ & $\begin{array}{l}42.7-2.2 \\
\quad(2.3-2.2)\end{array}$ & $\begin{array}{l}48.9-2.9 \\
\quad(3.0-2.9)\end{array}$ & $\begin{array}{l}48.4-2.6 \\
\quad(2.7-2.6)\end{array}$ \\
\hline Total No. of reflections & $137033(16361)$ & $252326(25224)$ & 342485 \\
\hline No. of unique reflections & $13566(1677)$ & $11870(1154)$ & $16117(1700)$ \\
\hline Completeness (\%) & $100.0(99.9)$ & $100.0(99.9)$ & $100.0(100.0)$ \\
\hline$R_{\text {merge }}(\%)$ & $4.5(1$ & $8.0(139.6)$ & $9.9(146.0)$ \\
\hline$R_{\text {meas }}(\%)$ & 4.7 (117.1) & $8.2(142.9)$ & $10.2(149.4)$ \\
\hline $\begin{array}{l}\text { Overall } B \text { factor from } \\
\text { Wilson plot }\left(\AA^{2}\right)\end{array}$ & 58 & 91 & 56 \\
\hline$\langle I / \sigma(I)\rangle$ & & 2 & 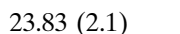 \\
\hline $\mathrm{CC}_{1 / 2}$ & $1.0(0.747)$ & $1.0(0.895)$ & $1.0(0.753)$ \\
\hline
\end{tabular}

$\dagger$ Data statistics refer to unmerged Friedel pairs.

(Qiagen, Hilden, Germany). The crystallization drops were prepared by mixing $100 \mathrm{nl}$ protein solution with $100 \mathrm{nl}$ reservoir solution with the help of a TTP Labtech Mosquito LCP crystal liquid-handling robot and were incubated against $70 \mu \mathrm{l}$ mother liquor in 96-well plates. The best condition [0.1 $M$ PCB (sodium propionate, sodium cacodylate and bis-tris propane in a 2:1:2 molar ratio; Qiagen) $\mathrm{pH} 8.0,25 \%$ PEG 1500] obtained from the initial screen was further improved by varying the $\mathrm{pH}$ and the concentration of PEG. The best diffracting crystals of wild-type Bem3 and the SeMet derivative grew in the form of hexagonal rods within $1 \mathrm{~d}$. The final crystallization conditions are summarized in Table 2.

\subsection{Data collection and processing}

Individual hexagonal rods were harvested, cryoprotected in mother liquor supplemented with $10 \%(v / v)$ glycerol and flashcooled in liquid nitrogen prior to data collection. The Bem3 crystals were maintained at $100 \mathrm{~K}$ and the collection of X-ray diffraction data was performed on beamline X10SA at the
Table 4

Refinement statistics for Bem $3_{500-765}$.

\begin{tabular}{ll}
\hline Resolution range $(\AA)$ & $42.7-2.2$ \\
Completeness (\%) & 99.96 \\
No. of reflections & 13565 \\
No. of reflections, test set & 679 \\
Final $R_{\text {cryst }}(\%)$ & 21.2 \\
Final $\left.R_{\text {free }} \%\right)$ & 23.4 \\
R.m.s. deviations & \\
$\quad$ Bond lengths $(\AA)$ & 0.002 \\
Bond angles $\left(^{\circ}\right)$ & 0.572 \\
No. of non-H atoms & 1787 \\
$\quad$ Protein & 21 \\
$\quad$ Water & \\
Average $B$ factors $\left(\AA^{2}\right)$ & 81 \\
$\quad$ Protein & 62 \\
Water & \\
Ramachandran plot & \\
Favoured $(\%)$ & 97.6 \\
$\quad$ Allowed $(\%)$ & 2.4 \\
$\quad$ Outliers $(\%)$ & 0 \\
\hline
\end{tabular}

Swiss Light Source (SLS), Paul Scherrer Institute, Villigen, Switzerland. The data were indexed and integrated with $X D S$ and scaled with XSCALE (Kabsch, 2010a,b). Data statistics are described in Table 3.

\subsection{Structure solution and refinement}

Initial phases and an initial model were obtained using the data set from the SeMet derivative of L688M Bem3 $3_{500-750}$ (containing a total of six SeMet residues) with phenix.autosol (Terwilliger et al., 2009). This resulted in an initial model with 82 amino-acid residues built (BAYES-CC $=44.3 \pm 9.6, R_{\text {work }}=$ $\left.34.3 \%, R_{\text {free }}=37.9 \%\right)$ and was followed by automated model building in phenix.autobuild $\left(R_{\text {work }}=27.2 \%, R_{\text {free }}=30.0 \%\right)$ (Terwilliger et al., 2008). The model was iteratively improved by manual model building in Coot (Emsley et al., 2010) and refinement with phenix.refine (Afonine et al., 2005) against the native data set for Bem3 $3_{500-765}$. Validation of the structure was performed with MolProbity (Chen et al., 2010). Refinement statistics can be found in Table 4.

\section{Results and discussion}

The crystal structure of the tandem PX-PH domains shows the well characterized folds of both protein domains as reported previously (Riddihough, 1994; Bravo et al., 2001). The model contains amino acids 502-629 belonging to the PX domain and 636-737 of the $\mathrm{PH}$ domain, but the linker region (amino acids 630-635) between the domains as well as the loops between $\beta 1_{\mathrm{PH}}$ and $\beta 2_{\mathrm{PH}}$ (amino acids 647-651) and $\beta 6_{\mathrm{PH}}$ and $\beta 7_{\mathrm{PH}}$ (amino acids 709-715) within the PH domain were flexible and could not be resolved. Even though six amino acids are missing between the two domains, the presented structural assembly within the asymmetric unit represents the only possible arrangement, and a different connectivity between the PX and PH domains is excluded because the positions of the respective $\mathrm{C}$ - and $\mathrm{N}$-termini are too remote. Using the native data set only, the sequence could not be unambiguously assigned within parts of the $\mathrm{PH}$ domain because of a lack of 
electron density for the side chains (especially within $\beta 4_{\mathrm{PH}}$; see Fig. 1). We therefore used the anomalous signal from crystals of SeMet-labelled K680M Bem3 $3_{500-750}$ and L688M Bem3 $3_{500-750}$ in order to correctly assign the positions of amino acids in this region (the electron density is shown in Fig. 1a).

As outlined in $\S 1$, both the PX and PH domains have been implicated in binding to PIPs and, besides other possible functions, mediate membrane binding and localization in cells. Strikingly, the PX domain of Bem3 contains basic residues (for example Lys551 and Arg592/Lys593) at similar positions compared with other PX domains, which have previously been termed basic motifs I and II, respectively, and have been shown to be involved in PIP binding (Sato et al., 2001). A similar observation also holds true for the $\mathrm{PH}$ domain (basic residues Arg644, Arg645 and Arg658), with similar relative positions compared with the PH domain of, for example, PLC $\delta$ (see the alignment in Fig. 1c; Lemmon, 2007). Positively charged residues within this part of the protein consisting of strands $\beta 1_{\mathrm{PH}}$ and $\beta 2_{\mathrm{PH}}$ and the connecting loop have also previously been identified as an important lipid-binding motif (Isakoff et al., 1998). This motif consists of the first lysine at the end of $\beta 1_{\mathrm{PH}}$ and an arginine in the middle of $\beta 2_{\mathrm{PH}}$, which both interact with adjacent phosphate head groups of PIP2 (Ferguson et al., 1995, 2000). The canonical lysine is, however, replaced by an arginine in the $\mathrm{PH}$ domain of Bem3. This arginine (Arg644) is well conserved among PH domains lacking the canonical lipid-binding sequence (Anand et al., 2012; Macia et al., 2008). The crystal structure of the PH domain of Slm1 (PDB entry 4a6k) revealed that the corresponding Arg478 interacts with PIPs (Anand et al., 2012).
Specific point mutations introduced at this position in Slm1 (Gallego et al., 2010) and the PH domain of EFA6 (Macia et al., 2008) resulted in mislocalization of the respective proteins, further signifying the role of this arginine in ligand binding. In line with these findings, an analysis involving the mutation of basic residues within the $\beta 1_{\mathrm{PH}^{-}} \beta 2_{\mathrm{PH}}$ loop of yeast Bem3 (R644S, R645S and K647D) showed that this abolished binding of the PH domain to PIP2, rendering the protein incapable of correctly localizing to the polar site at the cell membrane (Mukherjee et al., 2013). In contrast to these mutations within the $\mathrm{PH}$ domain, a quadruple mutant (Y524W, R578S, L580S and F581M; Mukherjee et al., 2013) involving amino acids within the so-called 'membrane-interaction loop' (Cheever et al., 2001) of the PX domain exhibits wild-type localization of Bem3. Although the critical residues Lys551 and Arg592 of basic motifs I and II of the Bem3 PX domain are conserved in the majority of PX domains (Cheever et al., 2001), their role in the direct binding of PIPs has yet to be elucidated.

Interestingly, the putative membrane-binding sites of both domains (basic motifs I and II within the PX domain and the PIP-binding site within the $\mathrm{PH}$ domain) are oriented in a similar direction (Fig. 1a) and this part of the protein displays a large positively charged basic surface (Fig. $2 b$ ). The similar orientation thus suggests a possible synergy between the domains with regard to the recognition of PIPs within a membrane, both with respect to the affinity of binding and the possibility of the recognition of a distinct membrane or compartment within the cell by the relative abundance of PIPs.

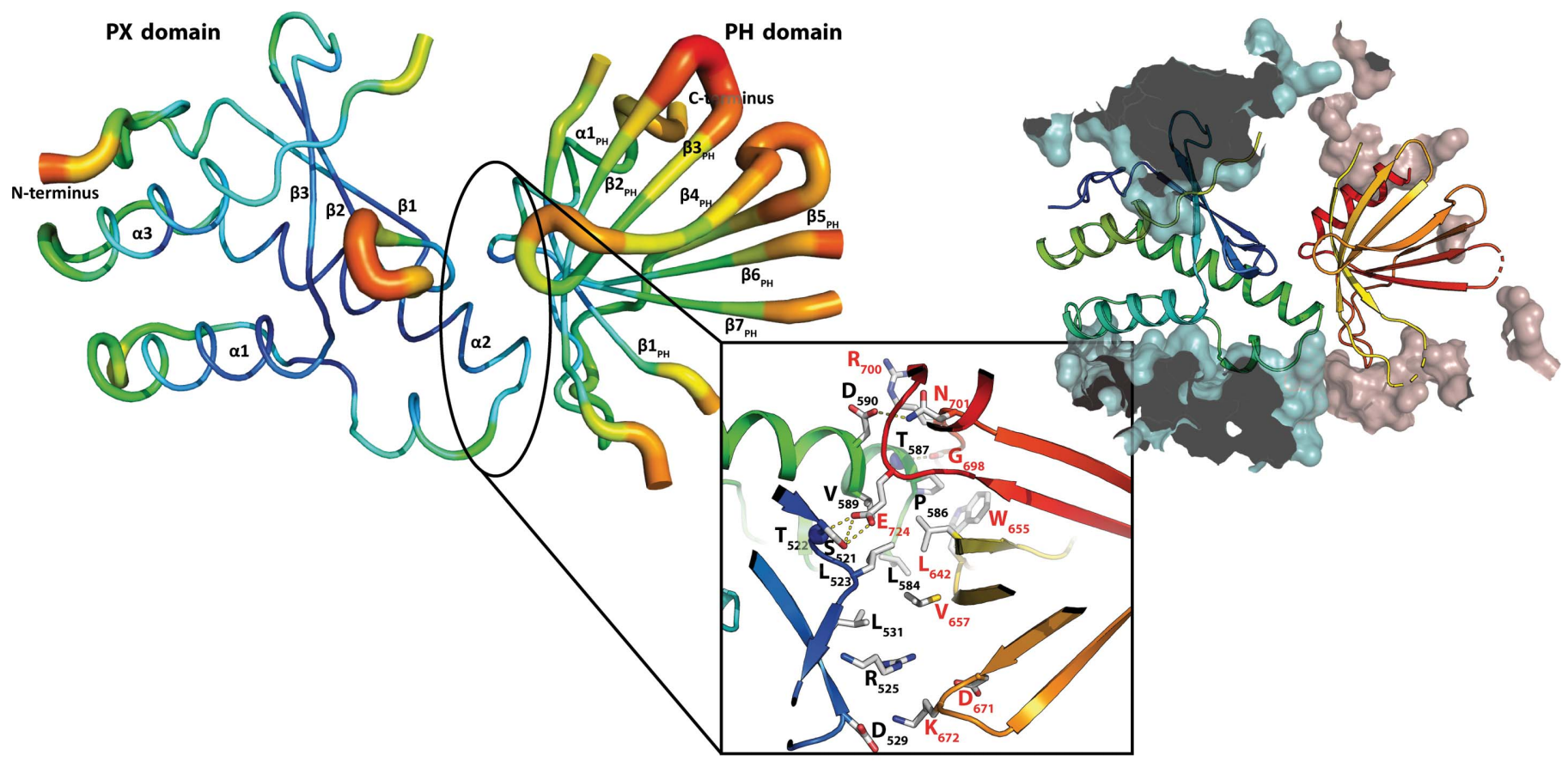

(a)

(b)

Figure 2

(a) $B$-factor representation of the PX and PH domains of Bem3 [putty representation from $P y M O L$; colours indicate low $B$ factors (blue) to high $B$ factors (red)]. The average $B$ factor for the whole structure is $81 \AA^{2}$ (PX domain, $71 \AA^{2}$; PH domain, $96 \AA^{2}$ ). Additionally, amino acids within the interface between the domains are shown. (b) Surfaces of neighbouring molecules in the crystal show that the PX domain has large contact areas (cyan surfaces), whereas the PH domain does not (red surfaces). 
The interface of $\sim 620 \AA^{2}$ between the PX and PH domains (calculated using PDBePISA; Krissinel \& Henrick, 2007) contains several hydrophobic interactions between Leu523, Leu531, Leu584, Pro586 and Val589 in the PX domain, and Leu642, Trp655 and Val657 in the PH domain, as well as hydrogen bonds (Thr587-Gly698, Ser521-Glu724, Thr522Glu724 and Asp590-Asn701) and ionic interactions (Arg525Asp671, Asp529-Lys672 and Asp590-Arg700) (Fig. 2), and many of these amino acids are conserved among Bem3 proteins from different organisms. Interestingly, a flexible relative mobility of the domains is indicated by the elevated $B$ factors, especially at the periphery of the PH domain facing away from the PX domain (Fig. 2a), resulting in average $B$ factors of 71 and $96 \AA^{2}$ for the PX and PH domains, respectively. The elevated $B$ factors of the $\mathrm{PH}$ domain can be understood by considering the different crystal contacts. Whereas the PX domain has large contact areas $\left(\sim 1210 \AA^{2}\right)$ with symmetry-related molecules, the $\mathrm{PH}$ domain has only small contact areas $\left(\sim 310 \AA^{2}\right.$; contact areas were calculated with PDBePISA; Krissinel \& Henrick, 2007; Fig. 2b), thus allowing the increased mobility. While we can only speculate on the possible role of this flexibility, it is conceivable that a less-than-rigid relative orientation of the two lipid-binding domains might allow different membrane curvatures in different specific situations.

\section{Conclusions}

In this publication, we present the three-dimensional structure of the tandem PX-PH domains of the yeast protein Bem3. The structure shows that the putative lipid-binding domains adopt a relative orientation that enables them to simultaneously bind to a membrane. Therefore, future studies should address the possibility of cooperativity between the domains with regard to membrane interaction as well as the resulting specificity with respect to the relative abundances of PIPs in a target membrane.

\section{Acknowledgements}

The authors are indebted to Dr Ingrid Renate Vetter and Georg Holtermann for support and maintenance of the crystallization facility at MPI Dortmund. We also thank the staff of beamline PXII of the Swiss Light Source at the Paul Scherrer Institute for the possibility of data collection.

\section{Funding information}

This work was funded by the Deutsche Forschungsgemeinschaft (DFG/ANR grant GO 284/8-1 and SFB 642).

\section{References}

Afonine, P. V., Grosse-Kunstleve, R. W. \& Adams, P. D. (2005). Acta Cryst. D61, 850-855.

Anand, K., Maeda, K. \& Gavin, A. C. (2012). PLoS One, 7, e36526. Baker, N. A., Sept, D., Joseph, S., Holst, M. J. \& McCammon, J. A. (2001). Proc. Natl Acad. Sci. USA, 98, 10037-10041.

Baumeister, M. A., Martinu, L., Rossman, K. L., Sondek, J., Lemmon, M. A. \& Chou, M. M. (2003). J. Biol. Chem. 278, 11457-11464.
Blomberg, N., Baraldi, E., Nilges, M. \& Saraste, M. (1999). Trends Biochem. Sci. 24, 441-445.

Bravo, J., Karathanassis, D., Pacold, C. M., Pacold, M. E., Ellson, C. D., Anderson, K. E., Butler, P. J. G., Lavenir, I., Perisic, O., Hawkins, P. T., Stephens, L. \& Williams, R. L. (2001). Mol. Cell, 8, 829-839.

Cheever, M. L., Sato, T. K., de Beer, T., Kutateladze, T. G., Emr, S. D. \& Overduin, M. (2001). Nature Cell Biol. 3, 613-618.

Chen, V. B., Arendall, W. B., Headd, J. J., Keedy, D. A., Immormino, R. M., Kapral, G. J., Murray, L. W., Richardson, J. S. \& Richardson, D. C. (2010). Acta Cryst. D66, 12-21.

DeLano, W. L. \& Lam, J. W. (2005). Abstr. Pap. Am. Chem. Soc. 230, u1371-u1372.

Ellson, C. D., Andrews, S., Stephens, L. R. \& Hawkins, P. T. (2002). J. Cell Sci. 115, 1099-1105.

Ellson, C. D., Gobert-Gosse, S., Anderson, K. E., Davidson, K., Erdjument-Bromage, H., Tempst, P., Thuring, J. W., Cooper, M. A., Lim, Z.-Y., Holmes, A. B., Gaffney, P. R., Coadwell, J., Chilvers, E. R., Hawkins, P. T. \& Stephens, L. R. (2001). Nature Cell Biol. 3, 679-682.

Emsley, P., Lohkamp, B., Scott, W. G. \& Cowtan, K. (2010). Acta Cryst. D66, 486-501.

Ferguson, K. M., Kavran, J. M., Sankaran, V. G., Fournier, E., Isakoff, S. J., Skolnik, E. Y. \& Lemmon, M. A. (2000). Mol. Cell, 6, 373-384.

Ferguson, K. M., Lemmon, M. A., Schlessinger, J. \& Sigler, P. B. (1995). Cell, 83, 1037-1046.

Gallego, O. et al. (2010). Mol. Syst. Biol. 6, 430.

Haslam, R. J., Koide, H. B. \& Hemmings, B. A. (1993). Nature (London), 363, 309-310.

Isakoff, S. J., Cardozo, T., Andreev, J., Li, Z., Ferguson, K. M., Abagyan, R., Lemmon, M. A., Aronheim, A. \& Skolnik, E. Y. (1998). EMBO J. 17, 5374-5387.

Kabsch, W. (2010a). Acta Cryst. D66, 125-132.

Kabsch, W. (2010b). Acta Cryst. D66, 133-144.

Kadota, J., Yamamoto, T., Yoshiuchi, S., Bi, E. \& Tanaka, K. (2004). Mol. Biol. Cell, 15, 5329-5345.

Karathanassis, D., Stahelin, R. V., Bravo, J., Perisic, O., Pacold, C. M., Cho, W. \& Williams, R. L. (2002). EMBO J. 21, 5057-5068.

Kavran, J. M., Klein, D. E., Lee, A., Falasca, M., Isakoff, S. J., Skolnik, E. Y. \& Lemmon, M. A. (1998). J. Biol. Chem. 273, 30497-30508.

Klein, D. E., Lee, A., Frank, D. W., Marks, M. S. \& Lemmon, M. A. (1998). J. Biol. Chem. 273, 27725-27733.

Krissinel, E. \& Henrick, K. (2007). J. Mol. Biol. 372, 774-797.

Lemmon, M. A. (2007). Biochem. Soc. Symp., pp. 81-93.

Lemmon, M. A. \& Ferguson, K. M. (2000). Biochem. J. 350, 1-18.

Lenoir, M. \& Overduin, M. (2013). Adv. Exp. Med. Biol. 991, 59-83.

Letunic, I., Copley, R. R., Pils, B., Pinkert, S., Schultz, J. \& Bork, P. (2006). Nucleic Acids Res. 34, D257-D260.

Lu, J., Garcia, J., Dulubova, I., Südhof, T. C. \& Rizo, J. (2002). Biochemistry, 41, 5956-5962.

Macia, E., Partisani, M., Favard, C., Mortier, E., Zimmermann, P., Carlier, M.-F., Gounon, P., Luton, F. \& Franco, M. (2008). J. Biol. Chem. 283, 19836-19844.

Macias, M. J., Musacchio, A., Ponstingl, H., Nilges, M., Saraste, M. \& Oschkinat, H. (1994). Nature (London), 369, 675-677.

Mayinger, P. (2012). Biochim. Biophys. Acta, 1821, 1104-1113.

Mukherjee, D., Sen, A., Boettner, D. R., Fairn, G. D., Schlam, D., Bonilla Valentin, F. J., McCaffery, J. M., Hazbun, T., Staiger, C. J., Grinstein, S., Lemmon, S. K. \& Aguilar, R. C. (2013). J. Cell Sci. 126, 4560-4571.

Pei, J., Kim, B.-H. \& Grishin, N. V. (2008). Nucleic Acids Res. 36, 2295-2300.

Ponting, C. P. (1996). Protein Sci. 5, 2353-2357.

Riddihough, G. (1994). Nature Struct. Biol. 1, 755-757.

Saraste, M. \& Hyvönen, M. (1995). Curr. Opin. Struct. Biol. 5, $403-$ 408.

Sato, T. K., Overduin, M. \& Emr, S. D. (2001). Science, 294, 18811885. 
Seet, L. F. \& Hong, W. (2006). Biochim. Biophys. Acta, 1761, 878-896. Song, X., Xu, W., Zhang, A., Huang, G., Liang, X., Virbasius, J. V., Czech, M. P. \& Zhou, G. W. (2001). Biochemistry, 40, 8940-8944.

Stahelin, R. V., Ananthanarayanan, B., Blatner, N. R., Singh, S., Bruzik, K. S., Murray, D. \& Cho, W. (2004). J. Biol. Chem. 279, 54918-54926.

Takeuchi, H., Kanematsu, T., Misumi, Y., Sakane, F., Konishi, H., Kikkawa, U., Watanabe, Y., Katan, M. \& Hirata, M. (1997). Biochim. Biophys. Acta, 1359, 275-285.

Terwilliger, T. C., Adams, P. D., Read, R. J., McCoy, A. J., Moriarty, N. W., Grosse-Kunstleve, R. W., Afonine, P. V., Zwart, P. H. \& Hung, L.-W. (2009). Acta Cryst. D65, 582-601.

Terwilliger, T. C., Grosse-Kunstleve, R. W., Afonine, P. V., Moriarty, N. W., Zwart, P. H., Hung, L.-W., Read, R. J. \& Adams, P. D. (2008). Acta Cryst. D64, 61-69.
Van Duyne, G. D., Standaert, R. F., Karplus, P. A., Schreiber, S. L. \& Clardy, J. (1993). J. Mol. Biol. 229, 105-124.

Worthylake, D. K., Rossman, K. L. \& Sondek, J. (2004). Structure, 12, 1078-1086.

Xing, Y., Liu, D., Zhang, R., Joachimiak, A., Songyang, Z. \& Xu, W. (2004). J. Biol. Chem. 279, 30662-30669.

Xu, Y., Seet, L. F., Hanson, B. \& Hong, W. (2001). Biochem. J. 360, 513-530.

Yoon, H. S., Hajduk, P. J., Petros, A. M., Olejniczak, E. T., Meadows, R. P. \& Fesik, S. W. (1994). Nature (London), 369, 672-675.

Yu, J. W., Mendrola, J. M., Audhya, A., Singh, S., Keleti, D., DeWald, D. B., Murray, D., Emr, S. D. \& Lemmon, M. A. (2004). Mol. Cell, 13, 677-688.

Zheng, Y., Cerione, R. \& Bender, A. (1994). J. Biol. Chem. 269, 23692372. 